\title{
Systematiske oversikter og kvalitativ forskning
}

\author{
Rigmor C. Berg ${ }^{1}$ og Heather Munthe-Kaas ${ }^{2}$ \\ 1) Seksjon for forebyggende, helsefremmende og organisatoriske tiltak, Nasjonalt kunnskapssenter for helsetjenesten \\ 2) Seksjon for velferdsforskning, Nasjonalt kunnskapssenter for helsetjenesten \\ E-post: rigmor.berg@kunnskapssenteret.no Telefon: 46400456
}

\begin{abstract}
SAMMENDRAG
Interessen for å samle og syntetisere kvalitative studier i systematiske oversikter er voksende. Det pekes blant annet på at sammenstillinger av kvalitativ forskning har stor verdi når det gjelder potensialet til å informere politikk og praksis. Systematiske oversikter om effekt gir innsikt i hvorvidt et tiltak virker; systematiske oversikter med kvalitativ forskning gir innsikt $\mathrm{i}$ hvordan og hvorfor eventuelle virkninger oppstår. Nytten av denne type oversikter erkjennes nå bl.a. av internasjonale organisasjoner som Cochrane og Campbell-samarbeidene. I Cochrane-håndboka vises det til at kvalitativ forskning kan bidra med nyttig informasjon på flere måter: Kvalitative datasett kan informere, styrke, utvide og supplere systematiske oversikter om effekt av tiltak. Metodene for gjennomføring av oversikter med kvalitativ forskning er i rask utvikling, og det fins for øyeblikket ingen standard tilnærming. Når det gjelder søk etter kvalitative studier må disse ofte være bredere, men forøvrig gjelder mange av de samme prinsippene som for litteratursøk innen systematiske oversikter om effekt av tiltak. Det forskes på og debatteres om hva slags kriterier som bør benyttes i utvelgelsen av kvalitative studier og hvorvidt man skal ekskludere studier basert på metodologisk kvalitet. Det fins flere ulike måter å syntetisere resultater fra kvalitative studier på, og det er også mulig å sammenstille resultater fra både kvalitative og kvantitative studier i én analyse. De mest hyppig brukte metodene er metaetnografi og tematisk analyse.
\end{abstract}

Berg RC, Munthe-Kaas H. Systematic reviews in qualitative research. Nor J Epidemiol 2013; 23 (2): 131-139.

\section{ENGLISH SUMMARY}

There is growing interest in summarising and synthesising qualitative research in systematic reviews. Among other things, this indicates an increasing appreciation for the potential role of qualitative evidence in informing policy and practice. While systematic reviews of effect studies can establish whether an intervention works, systematic reviews of qualitative research can offer insights into the "how" and "why" of potential effects. The importance of such questions, and the value of systematic reviews of qualitative research, is now recognized by a number of international organizations, including the Cochrane and Campbell Collaborations. The Cochrane Handbook describes four ways in which qualitative research can contribute to evidence-based practice, namely by informing, enhancing, extending, and supplementing systematic reviews of the effect of interventions. The methodology for conducting reviews of qualitative research is rapidly developing, and at present there is no standard approach. Systematic searches for qualitative research are often more broadly cast but otherwise follow many of the same principles of a literature search within a systematic review of effect. There are ongoing debates and research regarding criteria for inclusion of studies in general, and whether to include studies of low methodological quality in particular. An array of methods to synthesise qualitative evidence exists, and such evidence may also be synthesised together with quantitative evidence. Meta-ethnography and thematic analysis are the most commonly used synthesis methods.

This is an open access article distributed under the Creative Commons Attribution Licence, which permits unrestricted use, distribution, and reproduction in any medium, provided the original work is properly cited.

\section{BAKGRUNN}

Interessen for å samle og syntetisere kvalitative studier i systematiske oversikter er voksende. Metoder og terminologi er i rask utvikling, og etablerte standarder mangler. For systematiske oversikter som sammenstiller kvalitative studier, enten alene eller i kombinasjon med kvantitative studier, bruker vi her benevnelsen "oversikter med kvalitativ forskning." Begrepsfloraen om tematikken er rik. Uttrykket "kvalitativ metasyntese" ble først brukt i 1985 med henvisning til sammenstilling av flere kvalitative studier (1). Et av de første verkene om en spesifikk metode for å sammenstille flere kvalitative studier er Noblit og Hares bok om metaetnografi fra 1988 (2).

Mye av grunnarbeidet med å utvikle metoder for å sammenstille resultater fra kvalitative studier er gjennomført i helse- og utdanningsfeltet (3). Den første kvalitative evidenssyntesen innen helse ble publisert i 1994 (4) men i perioden 2005-2008 fordoblet antallet seg, og i dag fins over 200 publiserte oversikter med kvalitativ forskning innen helse, i tillegg til mange innen andre fag, som utdanning og velferd (5). Det anslås at systematiske oversikter med kvalitativ forsk- 


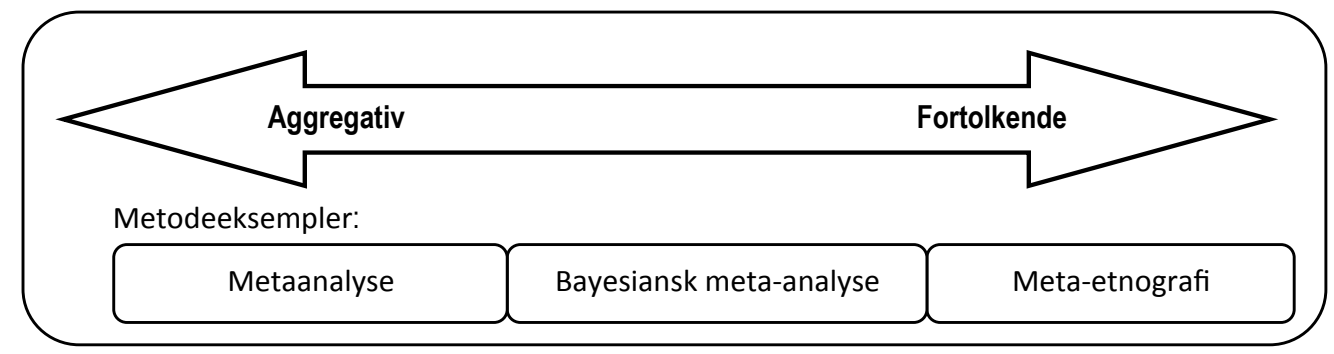

Figur 1. Kontinuum av evidenssynteser.

ning utgjør $0,5 \%$ av forskningsartiklene i de ti høyest rangerte sykepleietidsskriftene (6). Publikasjonsanalyser tyder på at oversikter med kvalitativ forskning er i ferd med å spre seg fra sykepleieforskningen, der de tradisjonelt har stått sterkest, til andre helse- og sosialfag (7).

Metodene for gjennomføring av en systematisk oversikt med kvalitativ forskning er mindre utprøvd enn for systematiske oversikter med kvantitative studier (om effekt av tiltak), med færre utførte oversikter å lære fra. Det går også en større debatt om hvorvidt og hvordan en best kan utføre slike oversikter (8-10). Enkelte hevder for eksempel at kvalitativ forskning ikke er generaliserbar, og at man ved å sammenstille flere kvalitative studier risikerer å av-kontekstualisere resultatene og feilaktig anta at resultatene er forenbare (11-12). Andre igjen framhever at sammenstilling av kvalitativ forskning introduserer en ny æra for generaliserbar kvalitativ teoriutvikling (13) og har stor verdi når det gjelder potensialet for å informere politikk og praksis (11,14-16).

På samme måte som det fins mange ulike studiedesign i primærforskningen, er det også stor bredde når det gjelder sammenstilling av studier i systematiske oversikter. Dette er illustrert i figur 1, som er inspirert av Dixon-Wood og kollegers (8) forståelse av Noblit og Hare's fremstilling av forskjellene mellom aggregative (integrerende) og fortolkende (interpretive) evidenssynteser (2).

Dixon-Wood og kolleger (8) hevder at de fleste evidenssynteser inneholder elementer av både aggregering og fortolkning. Kort fremstilt viser figur 1 at man $i$ den ene enden av spekteret finner den aggregerende tilnærmingen. Den kombinerer (oftest kvantitative) data, gjerne i meta-analyser, som oftest for å kunne trekke slutninger om kausalitet. Aggregative synteser er nærmere beskrevet av Jamtvedt og Smedslund i dette nummeret av Norsk Epidemiologi $(17,18)$. Mot midten av spekteret er tilnærminger som integrerer flere datasett i samme systematiske oversikt, gjerne ved at kvalitative forskningsresultater brukes til å supplere informasjon fra analyser av kvantitative datasett om effekt av tiltak. Bayesiansk meta-analyse er kanskje den mest kjente metoden for denne type tilnærming. I den andre enden av spekteret finner vi den fortolkende syntesen. I en slik tilnærming er oppmerksomheten rettet mot induksjon og tolkning av data, utvikling av begreper, og utvikling og spesifisering av teorier som integrerer disse begrepene. Metaetnografi er en stadig hyppigere brukt metode for fortolkende syntese av studieresultater.

Denne artikkelen tar for seg tematikk vedrørende bruk av kvalitativ forskning i systematiske oversikter. Slike oversikter vil hovedsakelig falle under en fortolkende tilnærming til evidenssyntese. Artikkelen gir et innblikk $\mathrm{i}$ fortrinnene og begrensningene ved oversikter med kvalitativ forskning, aktører på feltet og fremgangsmåter. De mange referansene gitt underveis er ment å veilede de som ønsker å fordype seg mer $\mathrm{i}$ temaet. Eksempler og våre egne erfaringer med slike oversikter gis underveis.

\section{KVALITATIV FORSKNING}

Først noe kort om hva kvalitativ forskning er: Kvalitative forskningsmetoder brukes for å undersøke og beskrive sosiale prosesser, opplevelser og erfaringer slik de oppfattes og uttrykkes av individer. Kvalitativ forskning er nyttig når man skal besvare spørsmål som "Hva betyr...?", "Hvordan foregår...?", eller "Hvordan opplever...?" (19).

Datainnsamlingen skjer som regel gjennom intervjuer, fokusgrupper eller observasjoner. Vanligvis har man et relativt lite utvalg deltakere og ønsker å oppnå et rikt, beskrivende datamateriale. Kvalitative data består som oftest av tekst og kan analyseres på ulike måter, for eksempel via fenomenologisk, narrativ eller diskursiv analyse. Felles for de ulike analysemetodene er at forskerne søker etter mening i datamaterialet for å generere nye hypoteser og begreper. Funnene presenteres $\mathrm{i}$ et beskrivende og fortellende format, med utdrag fra datamaterialet for å underbygge og illustrere funnene (20-21). De fleste forskere som benytter kvalitative metoder antar en konstruktivistisk erkjennelsesteori: virkeligheten fins ikke "der ute", men er konstruert av sosiale, historiske og individuelle livssituasjoner (22). Kvalitativ forskning kan utføres som et enkeltstående prosjekt eller i tandem med andre forskningsprosjekt. For eksempel kan kvalitativ forskning utført før og parallelt med en kontrollert studie brukes til å utforske hva slags tiltak som er aktuelle å prøve ut, hvilke utfallsmål som er de viktige å registrere, og hvordan tiltak best kan iverksettes i praksis. 


\section{SYSTEMATISKE OVERSIKTER MED KVALITATIV FORSKNING}

Oversikter med kvalitative data er nyttige av flere grunner. Først og fremst gir de et grundigere og mer presist svar på spørsmål om "hvordan" og "hvorfor" enn enkeltstudier og vil derfor ha større utsagnskraft enn hver enkelt studie har. De kan, og har ofte som mål å generere mer omfattende og generaliserende teori, og dermed gjøre resultater fra kvalitativ forskning mer relevant for grupper som helsepolitikere, klinikere og forskere $(14,23)$. Hvis kvalitativ forskning som belyser samme spørsmål ikke sammenstilles risikerer man å gå glipp av nyttig informasjon, eller til om med forvrenge evidensgrunnlaget (7). Oversikter med kvalitativ forskning kan legge større bredde i perspektiver og dybde $\mathrm{i}$ resultater til systematiske oversikter om effekt ved å fokusere på opplevelser og holdninger blant dem som tiltaket var rettet mot, og dermed hvilke tiltak som vil være akseptable og potensielt effektive (9,24-25). En oversikt med kvalitativ forskning kan også gi en grundig innsikt om forhold som begrenser evt. letter innføringen av et tiltak (se f.eks. (26)), og hvordan man kan oppnå endring. Kvalitative data kan også bidra til mulige forklaringer når effektstudier viser sprikende resultater (21).

Systematiske oversikter med kvalitative studier, som hovedsakelig vil falle innenfor en fortolkende tilnærming, innebærer både induksjon og tolkning av data fra de inkluderte studiene. Begreper som er identifisert i primærstudiene blir innordnet $\mathrm{i}$ en høyere orden teoretisk struktur. Som regel betyr dette at forskerne sammenligner og kontrasterer resultater fra de individuelle studiene for å oppnå enighet om en ny, høyere konstruksjon av et fenomen. Hovedformålet er å produsere en ny og integrert forståelse av funnene, som går ut over den forståelsen som fremgår i de individuelle studiene, og som leder fram til en mer presis tolkning av et fenomen $(8,27)$. Hovedresultatet $i$ en fortolkende syntese er vanligvis utvikling av teori, for eksempel forklaring på barns opplevelse av fedmeoperasjon eller hvorfor mange ikke fullfører slanketiltak.

\section{AKTøRER OG PRODUSENTER AV OVER- SIKTER MED KVALITATIV FORSKNING}

Oversikter med kvalitativ forskning fremmes gjennom flere internasjonale organisasjoner. Cochranesamarbeidet har relativt nylig åpnet for å gi plass til kvalitativ forskning i sine systematiske oversikter, og for øyeblikket er en håndfull Cochrane-oversikter med kvalitativ evidens under utarbeidelse (se (28-33)). Innenfor Cochrane-samarbeidet har det siden 1998 eksistert et nettverk for utvikling av metoder for systematiske oversikter med kvalitativ forskning. Cochrane Collaboration Qualitative \& Implementation Methods Group publiserte nylig et kapittel i Cochrane håndboka der det skisseres hvordan kvalitativ forskning kan bidra inn i Cochrane-oversikter (34). Også Campbell- samarbeidet publiserer systematiske oversikter som inkluderer kvalitative studier (35), se f.eks. Patterson et al, og van der Laan et al (36-37). Forskere ved Evidence for Policy and Practice Information and Coordinating Centre (EPPI) (38) og Joanna Briggs Instituttet (39-40) har utviklet flere metoder for sammenstilling av kvalitativ forskning.

Enkelte forskere ved Kunnskapssenteret har erfaring i utarbeidelse av oversikter med kvalitativ forskning (f.eks. (41-46)), utvikling av en sjekkliste for oversikter med kvalitativ forskning (47) og et system for å vurdere påliteligheten til kunnskapsgrunnlaget for hvert enkelt funn i oversikter med kvalitativ forskning (kalt CerQual, se $(29,45)$ ).

\section{FRAMGANGSMÅTE}

Det fins ingen standard tilnærming til oversikter med kvalitativ forskning $(8,48-49)$. I Cochrane-håndbokas kapittel 20 beskrives hvordan oversiktsforfattere kan benytte kvalitativ forskning i Cochrane-oversikter om effekt, hvordan de kan søke etter og kritisk vurdere kvalitativ forskning, og hvordan de kan trekke ut og syntetisere resultater fra slik forskning. I håndboka vises det til at kvalitativ forskning kan bidra med nyttig informasjon på fire måter (disse er basert på Popay (16)). Kvalitative datasett kan informere (inform), styrke (enhance), utvide (extend) og supplere (supplement) Cochrane-oversikter om effekt:

1. Informere systematiske oversikter ved å bruke kunnskap fra kvalitativ forskning til å definere og avgrense spørsmålet. Dette sikrer at oversikten inkluderer aktuelle studier og adresserer viktige utfall, slik at den blir mest mulig nyttig for potensielle brukere.

2. Styrke systematiske oversikter ved å syntetisere evidens fra kvalitativ forskning som kommer fram under leting etter forskning om effekt. Kvalitative data knyttet til tiltak kan brukes til å utforske spørsmål om hvordan tiltakene ble gjennomført.

3. Utvide vurderinger av effekt av tiltak ved å foreta et spesifikt søk etter, og en syntese av, kvalitative studieresultater for å vurdere spørsmål direkte knyttet til spørsmålet om effekt.

4. Supplere systematiske oversikter om effekt ved å sammenstille kvalitativ evidens om andre spørsmål enn de som er knyttet til effekt av tiltak (34) (vår oversettelse fra engelsk).

Generelt sett kan fremgangsmåten for oversikter med kvalitativ forskning, ifølge Finfgeld (14), forstås som en tre trinns prosess: 1) bestemme fokus for studien, 2) velge ut studier, og 3) analysere data. Nedenfor presenterer vi noen av vurderingene underveis $\mathrm{i}$ denne prosessen.

\section{Bestemme fokus}

Som i systematiske oversikter om effekt av tiltak er det viktig at også oversikter med kvalitative studier har et 
klart fokus for å kunne fremskaffe presise resultater. For systematiske oversikter med kvalitative studier har Eakin og Mykhalovskiy (50) foreslått at spørsmålet man ønsker å besvare kan være et "veiledende kompass heller enn et ubøyelig anker." I praksis ser det likevel ut til at de aller fleste oversiktene som inkluderer kvalitative studier starter med et fokusert spørsmål, men at dette gjerne er noe bredere enn de man ser i oversikter om effekt av tiltak $(5,7,9,14)$. For eksempel, spørsmålet Kane og medarbeidere (51) ønsket å besvare i sin oversikt var: Hva gjør foreldrerettede tiltak meningsfulle og nyttige for foreldre som har barn med emosjonelle og atferdsmessige problemer?

\section{Velge ut studier}

Mange av de samme prinsippene for litteratursøk innen systematiske oversikter om effekt av tiltak vil også gjelde for oversikter med kvalitativ forskning. Men litteratursøk etter kvalitative studier kan være mer komplekse og utfordrende enn søk etter randomiserte kontrollerte studier $(10,48,52)$. MEDLINE inkluderte MeSH-termen "qualitative research" først i 2003, mens CINAHL introduserte "qualitative study" i 1988. Det fins ingen database som tilsvarer Cochrane Controlled Trials Register innen kvalitativ forskning. En studie fra England viste at 55\% av inkluderte studier i tre systematiske oversikter med kvalitativ forskning var identifisert gjennom de fire databasene ASSIA, PsycINFO, CINAHL og PubMed. Selv om mye relevant kvalitativ litteratur kan identifiseres gjennom en håndfull databaser anbefalte forskerne likevel å søke bredt (53). Forbedringer introduseres stadig (se f.eks. (54-55)), bl.a. har Hedges prosjektet ved McMaster-Universitetet i Canada utviklet metodiske søkefiltre for kvalitative studier for databasene MEDLINE, CINAHL, PsycINFO og EMBASE (34).

Det debatteres om det er nødvendig med et uttømmende søk for oversikter med kvalitative studier (23). Noen mener at "rekruttering" av kvalitative studier kan være som i rekruttering av deltakere for en kvalitativ studie, dvs. teoretisk eller strategisk (56). Andre mener dette kan føre til at oversikten ikke lenger er systematisk (ikke eksplisitt og reproduserbar), og at man går glipp av viktige studier og derfor ikke oppnår fullgod forståelse av fenomenet man undersøker (57-58). Trenden ser ut til å gå i retning av uttømmende søk (59).

Det hersker også debatt om klare kriterier for utvelgelse av kvalitative studier av høy metodisk kvalitet (50,60-61). Debatten angår særlig hvorvidt én standardisert sjekkliste kan benyttes på alle typer kvalitative studier. Det er identifisert over 100 forslag for kvalitetsvurdering av kvalitative studier $(23,34)$. Ifølge Harden (62) er ett av problemene med de fleste eksisterende sjekklister at de behandler kvalitative studier som homogene, uten differensiering av de ulike spørsmålene som besvares av kvalitativ forskning eller de ulike metodene som benyttes. Det foregår mye arbeid med å utarbeide sjekklister for metodisk kvalitetsvurdering av kvalitative studier (f.eks (50)).
Et relatert spørsmål er hvorvidt man skal ekskludere studier basert på en vurdering av metodologisk kvalitet. For å bedre metodene for fortolkende tilnærminger debatteres og forskes det på dette, og praksis varierer som det gjør for aggregative tilnærminger. Noen oversiktsforfattere ekskluderer studier av lav(ere) metodologisk kvalitet (11), noen benytter studier av lavere metodologisk kvalitet i mindre grad enn de av høyere kvalitet (63), mens andre igjen benytter funn som man kan stole på og ekskluderer funn man ikke kan stole på fra én og samme studie $(12,58)$. Carroll og medarbeidere (64), som testet hvorvidt ekskludering av studier av lav(ere) metodisk kvalitet hadde implikasjoner for resultatene i tre oversikter, fant at ekskludering av slike studier ikke påvirket resultatene. I stedet var prosessen tidsbesparende og økte den interne validiteten til funnene i oversiktene.

\section{Analysere data}

Det fins flere ulike måter å syntetisere resultater fra kvalitative studier på, og det er også mulig å sammenstille resultater fra både kvalitative og kvantitative studier i samme analyse (mixed-methods). Det gjenstår metodiske utfordringer for disse prosessene og mye arbeid for utvikling av gode syntesemetoder pågår (se f.eks. $(8,49,65))$. En sentral utfordring gjelder hvilke typer data som kan syntetiseres. Mens noen forskere motsetter seg syntetisering av resultater fra studier med ulike erkjennelsesteoretiske perspektiver mener andre at dette fører til større bredde og dybde i beskrivelsen av et fenomen, samt at det er en nyttig form for triangulering av resultater (14). En grundig beskrivelse av de erkjennelsesteoretiske overveielsene er bl.a. gitt av Zimmer, som tilrår syntetisering av kvalitative funn på tvers av filosofiske og metodiske retninger (66).

\section{MANGFOLD AV SYNTESETILNARMINGER}

Oversikter viser at de mest hyppig brukte metodene for å sammenstille kvalitativ forskning er: metaetnografi, tematisk syntese, meta-studie, meta-oppsummering, kritisk-fortolkende syntese, kvalitativ cross-case analyse, grounded teorisyntese, narrative analyse, og meta-fortolkning $(5,9)$.

\section{Metaetnografi}

Metaetnografi er en syntesetilnærming som ble spesielt utviklet av Noblit og Hare (2) for å syntetisere kvalitative studier. Syntesemetoden innebærer tre hovedstrategier. Først, identifisering av hovedtema eller begreper i hver studie. Deretter følger utforskning av forbindelsene og ulikhetene mellom disse: forskeren søker å forstå og overføre ideer, konsepter og metaforer på tvers at studiene. Til slutt kommer det Noblit og Hare kaller "lines of argument synthesis", som omfatter oppbygging av en generell tolkning grunnet i resultatene fra hver enkelt studie. Noen av ulempene med metoden er at den ikke gir råd om utvelging av studier og metodisk kvalitetsvurdering. På den annen 
side er metoden systematisk, beholder individuelle nyanser fra primærstudiene, og kan håndtere både kvalitative og kvantitative data (8). Andre forskere fremhever metodens transparens (25) og evne til å generere en omfattende og generaliserende teori (3). Metaetnografi er den mest brukte metoden for systematiske oversikter som inkluderer kvalitative studier $(5,9)$. Et eksempel på metaetnografi er Pound og medforfatteres oversikt om medisinvegring (67). Den inkluderte 37 primærstudier og konkluderte med at den viktigste grunnen til at folk ikke tar medisinene sine som foreskrevet er bekymringer om bivirkninger.

\section{Tematisk syntese}

Metoden er utviklet av forskere ved EPPI-senteret for å takle spørsmål om behov, hensiktsmessighet, aksept og effekt av tiltak. Gjennom en beskrivende syntese av kvalitative data fra flere studier utvikles analytiske temaer, som kan integreres med kvantitative resultater om nytte og skade av tiltak. Én fordel med metoden er at innsikt ervervet fra syntesen av kvalitative studier muliggjør utforskning av statistisk heterogenitet på måter som det ville være vanskelig å planlegge på forhånd $(10,24)$. I følge Dixon-Woods og medarbeidere (8) mangler metoden klarhet angående fremgangsmåten, blant annet om analysen skal være beskrivende eller fortolkende. Tematisk syntese er stort sett, men ikke utelukkende, benyttet for systematiske oversikter som analyserer kvalitative data sammen med kvantitative data om helsefremmende tiltak $(5,9)$. Ofte siterte eksempler på tematisk syntese er EPPI-senterets systematiske oversikter om faktorer som fremmer og hindrer god mental helse, fysisk aktivitet og sunt kosthold blant ungdom (68-70). Forskere ved Kunnskapssenteret fant metoden logisk og anvendbar da de benyttet den i en oversikt om faktorer som fremmer og forhindrer kvinnelig kjønnslemlestelse (41,71-72). Tematisk syntese ligner på narrativ analyse, som beskriver og sorterer data etter kategorier, gjerne etterfulgt av enkle tolkninger. Analysen benyttes noe ulikt av ulike forskere og kalles også narrativ oppsummering (8).

\section{Realistsyntese}

Realistsyntesen ble utviklet av de Britiske forskerne Pawson, Greenhalgh, Harvey og Walshe (73). De forklarer at det er en teoribasert tilnærming som søker å forklare "hva virker for hvem, under hvilke omstendigheter og hvordan." Byggesteinene i en realistsyntese er utfall, endringsmekanismer og kontekstuelle forhold. Endringsmekanismene er "motoren" bak atferdsendring og utgjør sammen med teorier som ligger til grunn for sosiale tiltak hoved-fokuset i realistsyntesen. Konteksten anses som viktig siden mekanismene vil virke på ulike måter avhengig av omstendighetene, slik som sosiokulturelle forhold. Evidens som samles inn og benyttes i realistsyntesen forstås $\mathrm{i}$ vid forstand og kan inkludere formelle studier men også ekspertuttalelser, medieoppslag og lignende (72-75). En av begrensningene er at metoden behandler all type evidens som like gyldig (pålitelig) (8). Realistsyntese er en metode som forskere ved Kunnskapssenteret har hatt god erfaring med, men den mangler transparens, er tidkrevende og stiller store krav til kompetanse innen flere metodefelt og ekspertise om helsetiltak $(42,76)$.

\section{Sammenligninger av ulike syntesemetoder}

Det fins som nevnt mange ulike syntesemetoder for kvalitative data, men hvor ulike er de egentlig? I sin kritiske gjennomgang av metoder for utarbeiding av oversikter med kvalitative data konkluderte BarnettPage og Thomas (77) at det fins både likheter og forskjeller mellom metodene, og at mange av forskjellene skyldes ulike erkjennelsesteoretiske ståsteder. Dette punktet beskrives godt også i Saini og Shlonskys bok (49). Funn fra en studie av Dixon-Woods og medarbeidere (57) er også informative. I en sammenligning av resultater fra en systematisk oversikt utført (tre ganger) med ulike syntesemetoder - narrativ syntese, metaetnografi og Bayesiansk meta-analyse - fant forskerne både fordeler og utfordringer ved hver metode. Både narrativ syntese og metaetnografi førte til strukturerte og logiske redegjørelser for forskningsgrunnlaget, der førstenevnte førte til en mer beskrivende redegjørelse og sistenevnte var mer eksplisitt orientert mot teoribygging. Også Lucas og medarbeidere (78) fant at de endte opp med de samme konklusjonene i sine oversikter, enten de benyttet narrativ eller tematisk syntese. Forskjellene i analysemetode lå i måten de behandlet studiekvalitet og heterogenitet. Mens disse forskerne, $\mathrm{i}$ likhet med Dixon-Wood og medarbeidere (57), fant at narrativ syntese var særlig egnet til å beskrive omfanget av eksisterende forskning og si noe om styrken på evidensen, så hadde tematisk analyse større potensial for å generere hypoteser. Det kan synes som om syntesevalg bør velges ut i fra både forskningsspørsmålet og hva resultatet skal brukes for.

\section{INTEGRERING AV KVALITATIV OG KVANTITA- TIV FORSKNING I EN SYSTEMATISK OVERSIKT}

Det blir stadig vanligere å finne systematiske oversikter som behandler flere eller brede spørsmål i én oversikt, og dermed ulike datasett. Men, som også andre forskere hevder (f.eks. $(24,79)$ ), så er en av hovedutfordringene for systematiske oversiktsforfattere integrering av ulike typer studier og resultater i én og samme systematiske oversikt (mixed-methods systematiske oversikter). Så langt er i hovedsak to metoder utviklet for slik integrering: Bayesiansk meta-analyse og EPPI-senterets integrerende metode.

Bayesiansk meta-analyse er en ofte sitert, men lite benyttet metode. Et kjennetegn på metoden er at den benytter kvalitativ forskning i avgrensning av oversikten, for å identifisere alle relevante variabler for inklusjon. Metoden kan følgelig vise hull i den kvantitative forskningen, om aspekter som kan være relevante for pasienten. To eksempler på bruk av metoden er oversiktene til Roberts et al, og Voils et al (80-81). 
EPPI-senteret i England har utviklet en metode for å integrere kvalitativ forskning med kontrollerte forsøk i systematiske oversikter $(24,68,82)$. Også andre forskere har benyttet denne metoden og anbefaler den (f.eks. $(45,78)$ ). Fremgangsmåten er i utgangspunktet enkel ved at man, ved hjelp av krysstabeller eller matriser, forsøker å forklare resultatene fra en syntese om effekt av tiltak (kvantitative effektstudier) ved hjelp av resultatene fra en syntese om pasientpreferanser (kvalitativ forskning). Tabulering av de to datasettene muliggjør en vurdering av hvordan pasientpreferanser matcher (ulike komponenter ved) tiltakene. I en vurdering av nytten av en slik tilnærming, skriver forfatterne at bruk av kvalitative studier i oversiktene også tilførte verdi ved at de klarla tiltakenes egnethet, muliggjorde undersøkelser rundt heterogeniteten i effektresultatene og identifiserte lovende tiltak for videre utvikling (83-84).
Eksempler på andre måter å integrere kvantitative og kvalitative datasett $i$ én og samme systematisk oversikt fins, noen av disse er nevnt tidligere i artikkelen, men disse metodene er mindre utviklet for å integrere kvalitativ og kvantitativ forskning (se f.eks. (85-87)).

\section{OPPSUMMERING}

Vi har her gitt en kort oversikt over systematiske oversikter med kvalitativ forskning. Nytten av slike oversikter inkluderer at de kan gi innsikt om forhold som begrenser evt. letter innføringen av tiltak, noe som er tilkjennegitt i bl.a Cochrane-samarbeidets aksept av oversikter som inkluderer kvalitative studier. Flere aspekter knyttet til utførelsen av slike oversikter er i rask utvikling, blant annet metoder for litteratursøk, metodisk kvalitetsvurdering og datasyntese.

\section{REFERANSER}

1. Stern P, Harris C. Women's health and the self-care paradox: a model to guide self-care readiness - clash between the client and nurse. Health Care Women Int 1985; 6: 151-163.

2. Noblit GW, Hare RD. Meta-ethnography: Synthesizing qualitative studies. Newbury Park, California: Sage, 1988.

3. Atkins S, Lewin S, Smith H, Engel M, Fretheim A, Volmink J. Conducting a meta-ethnography of qualitative literature: Lessons learnt. BMC Med Res Methodol 2008; 8: 21.

4. Jensen LA, Allen MN. A synthesis of qualitative research on wellness-illness. Qual Health Res 1994; 4: 349369.

5. Hannes K, Macaitis K. A move to more systematic and transparent approaches in qualitative evidence synthesis: update on a review of published papers. Qual Res 2012; 12: 402-442.

6. Mantzoukas S. The research evidence published in high impact nursing journals between 2000 and 2006: a quantitative content analysis. Int J Nurs Stud 2009; 6: 479-489.

7. Dixon-Woods M, Booth A, Sutton AJ. Synthesizing qualitative research: a review of published reports. Qual Res 2007; 7: 375-422.

8. Dixon-Wood M, Agarwal S, Jones D, Young B, Sutton A. Synthesising qualitative and quantitative evidence: a review of possible methods. J Health Serv Res Policy 2005; 10: 45-53.

9. Ring N, Jepson R, Ritchi K. Methods of synthesizing qualitative research studies for health technology assessment. Int J Technol Assess Health Care 2011; 27: 384-390.

10. Thomas J, Harden A. Methods for the thematic synthesis of qualitative research in systematic reviews. BMC Med Res Methodol 2008; 8: 45.

11. Campbell R, Pound P, Pope C, Britten N, Pill R, Morgan M, Donovan J. Evaluating meta-ethnography: a synthesis of qualitative research on lay experiences of diabetes and diabetes care. Soc Sci Med 2003; 56: 671-684.

12. Sandelowski M, Barroso J. Handbook for synthesising qualitative research. New York: Springer, 2007.

13. Bondas T, Hall EOC. Challenges in approaching meta-synthesis research. Qual Health Res 2007; 17: 113121.

14. Finfgeld D. Metasynthesis: The state of the art - so far. Qual Health Res 2003; 13: 893-904.

15. Newman M, Thompson C, Roberts AP. Helping practitioners understand the contribution of qualitative research to evidence-based practice. Evid Based Nurs 2006; 9: 4-7.

16. Popay J. Moving beyond effectiveness in evidence synthesis. London: National Institute for Health and Clinical Excellence, 2006.

17. Jamtvedt G. Systematiske oversikter om effect av tiltak. Norsk Epidemiologi 2013; 23: 119-124.

18. Smedslund G. Metaanalyse. Norsk Epidemiologi 2013; 23: 147-149.

19. Malterud K. Qualitative research: standards, challenges, and guidelines. Lancet 2001; 358: 483-488.

20. Pope C, Ziebland S, Mays N. Qualitative research in health care. Analysing qualitative data. BMJ 2000; 320: 114-116.

21. Thorne S. Data analysis in qualitative research. Evid Based Nurs 2000; 3: 68-70.

22. Kuper A, Reeves S, Levinson W. An introduction to reading and appraising qualitative research. $B M J 2008$; 337: a288. 
23. Dixon-Woods M, Agarwal S, Young B, Jones D, Sutton A. Integrative approaches to qualitative and quantitative evidence. London, NHS 2004. www.nice.org.uk/aboutnice/whoweare/aboutthehda/evidencebase/key papers/papersthatinformandsupporttheevidencebase/integrative_approaches_to_qualitative_and_quantitative_ evidence.jsp (22.06.2013).

24. Thomas J, Harden A, Oakley A, Oliver S, Sutcliffe K, Rees R, Brunton G, Kavanagh J. Integrating qualitative research with trials in systematic reviews. BMJ 2004; 328: 1010-1012.

25. Walsh D, Downe S. Meta-synthesis method for qualitative research: a literature review. J Adv Nurs 2005; 50: 204-211.

26. Harden A, Garcia J, Oliver S, Rees R, Shepherd J, Brunton G, Oakley A. Applying systematic review methods to studies of people's views: an example from public health research. J Epidemiol Community Health 2004; 58: $794-800$.

27. Thorne S, Jensen L, Kearney MH, Noblit G, Sandelowski M. Qualitative metasynthesis: Reflections on methodological orientation and ideological agenda. Qual Health Res 2004; 14: 1342-1365.

28. Campbell F, O'Neill PM, While A, McDonagh J. Interventions to improve transition of care for adolescents from paediatric services to adult services (Protocol). Cochrane Database Syst Rev 2012, Issue 4. Art. No.: CD009794. DOI: 10.1002/14651858.CD009794.

29. Glenton C, Colvin C, Carlsen B, Swartz A, Lewin S, Noyes J, Rashidian A. Barriers and facilitators to the implementation of lay health worker programmes to improve access to maternal and child health: qualitative evidence synthesis (Protocol). Cochrane Database Syst Rev 2013, Issue 2. Art. No.: CD010414. DOI: 10.1002/14651858.CD010414.

30. Jordan J, Rose L, Dainty KN, Noyes J, Clarke S, Blackwood B. Factors that impact on the use of mechanical ventilation weaning protocols in critically ill adults and children: a qualitative evidence-synthesis (Protocol). Cochrane Database Syst Rev 2012, Issue 5. Art. No.: CD009851. DOI: 10.1002/14651858.CD009851.

31. Leiknes KA, Berg RC, Smedslund G, Jarosch-von Schweder L, Øverland S, Hammerstrøm KT, Høie B. Electroconvulsive therapy for depression (Protocol). Cochrane Database Syst Rev 2011, Issue 5. Art. No.: CD009105. DOI: 10.1002/14651858.CD009105.

32. Lins S, Rücker G, Motschall E, Langer G, Antes G, Meyer G. Efficacy and experiences of telephone counselling for informal carers of people with dementia (Protocol). Cochrane Database Syst Rev 2011, Issue 5. Art. No.: CD009126. DOI: 10.1002/14651858.CD009126.

33. Rashidian A, Shakibazadeh E, Karimi- Shahanjarini A, Glenton C, Noyes J, Lewin S, Colvin C, Laurant M. Barriers and facilitators to the implementation of doctor-nurse substitution strategies in primary care: qualitative evidence synthesis (Protocol). Cochrane Database Syst Rev 2013, Issue 2. Art. No.: CD010412. DOI: $10.1002 / 14651858 . C D 010412$.

34. Noyes J, Popay J, Pearson A, Hannes K, Both A. Chapter 20: Qualitative research and Cochrane reviews. I: Higgins JPT, Green S, red. Cochrane handbook for systematic reviews. Version 5.1.0 [oppdatert mars 2011]. The Cochrane Collaboration, 2011. www.cochrane-handbook.org (22.06.2013).

35. Hannes K, Claes L, the Belgian Campbell Group. Learn to read and write systematic reviews: the Belgian Campbell Group as a local partner. Res Soc Work Pract 2007; 17: 748-753.

36. Patterson GT, Chung IW, Swang PG. The effects of stress management interventions among police officers and recruits. Campbell Syst Rev 2012; 7.

37. van der Laan P, Smit M, Busschers I, Aarten P. Cross-border trafficking in human beings: prevention and intervention strategies for reducing sexual exploitation. Campbell Syst Rev 2011; 9.

38. Oliver S, Harden A, Rees R, Shepherd J, Brunton G, Garcia J, Oakley A. An emerging framework for including different types of evidence in systematic reviews for public policy. Evaluation 2005; 11: 428-446.

39. Hannes K, Lockwood C. Pragmatism as the philosophical foundation for the Joanna Briggs meta-aggregative approach to qualitative evidence synthesis. J Adv Nurs 2011; 67: 1632-1642.

40. Pearson A, Wiechula R, Court A, Lockwood C. A re-consideration of what constitutes 'evidence' in the healthcare professions. Nurs Sci Q 2007; 20: 85-8.

41. Berg RC, Denison E, Fretheim A. Faktorer som fremmer og forhindrer kjønnslemlestelse. Rapport fra Kunnskapssenteret 2010; 23.

42. Berg RC, Denison E. Interventions to reduce the prevalence of female genital mutilation/cutting in African countries. Campbell Collaboration 2012; 9.

43. Glenton C, Lewin S, Scheel IB. Still too little qualitative research to shed light on results from reviews of effectiveness trials: A case study of a Cochrane review on the use of lay health workers. Implement Sci 2011; 6: 53 .

44. Munro SA, Lewin SA, Smith HJ, Engel ME, Fretheim A, et al. Patient adherence to tuberculosis treatment: A systematic review of qualitative research. PLoS Med 2007; 4: e238.

45. Munthe-Kaas HM, Hammerstrøm KT, Kurtze N, Nordlund KR. Effekt av og erfaringer med kontinuitetsfremmende tiltak i barnevernsinstitusjoner. Rapport fra Kunnskapssenteret 2013; 4. 
46. Larun L, Malterud K. Identity and coping experiences in Chronic Fatigue Syndrome: A synthesis of qualitative studies. Patient Educ Couns 2007; 69: 20-28.

47. Lewin S, Bosch-Capblanch X, Oliver S, Akl EA, Vist GE, Lavis JN, et al. Guidance for evidence-informed policies about health systems: Assessing how much confidence to place in the research evidence. PLoS Med 2012; 9: e1001187.

48. Mays N, Pope C, Popay J. Systematically reviewing qualitative and quantitative evidence to inform management and policy-making in the health field. J Health Serv Res Policy 2005; 10 (suppl 1): 6-20.

49. Saini M, Shlonsky A. Systematic synthesis of qualitative research. Oxford: Oxford University Press, 2012.

50. Eakin JM, Mykhalovski E. Reframing the evaluation of qualitative health research: reflections on a review of appraised guidelines in the health sciences. J Eval Clin Pract 2003; 9: 187-194.

51. Kane GA, Wood VA, Barlow J. Parenting programmes: a systematic review and synthesis of qualitative research. Child Care Health Dev 2007; 33: 784-793.

52. Barroso J, Gollop CJ, Sandelowski M, Meynell J, Pearce PF, Colins LJ. The challenges of searching for and retrieving qualitative studies. West J Nurs Res 2003; 5: 153-178.

53. Stansfield C, Kavanagh J, Brunton G, Rees R, Thomas J. Search wide and dig deep: identifying 'views' research for systematic reviews. Joint Cochrane and Campbell Colloquium 2010; Keystone, Colorado, USA.

54. Lloyd Jones M. Application of systematic review methods to qualitative research: practical issues. $J$ Adv Nurs 2004; 48: 271-278.

55. Wong G, Greenhalgh T, Westhorpe G, Buckingham J, Pawson R. RAMESES publication standards: metanarrative reviews. BMC Med 2013; 11: 20.

56. Booth A. Cochrane or cock-eyed? How should we conduct systematic reviews of qualitative research? Qualitative Evidence-based Practice Conference 2001; Coventry UK. www.leeds.ac.uk/educol/documents/ 00001724.htm (22.06.2013).

57. Dixon-Woods M, Bonas S, Booth A, Jones DR, Miller T, Sutton AJ, Shaw RL, Smith JA, Young B. How can systematic reviews incorporate qualitative research? A critical perspective. Qual Res 2006; 61: 27-44.

58. Jensen LA, Allen MN. Meta-synthesis of qualitative findings. Qual Health Res 1996; 6: 553-560.

59. Finfgeld-Connett D. Generalizability and transferability of meta-synthesis research findings. J Adv Nurs 2010; 66: 246-254.

60. Barbour RS, Barbour M. Evaluating and synthesizing qualitative research: the need to develop a distinctive approach. J Eval Clin Pract 2003; 9: 179-186.

61. Popay J. Moving beyond floccinaucinihilipilification: enhancing the utility of systematic reviews. $J$ Clin Epidemiol 2003; 58: 1079-1080.

62. Harden A. A review of tools for assessing the quality of qualitative studies: implications for systematic reviews. Cochrane Colloquium 2004; Ottawa Canada.

63. Attre P. Growing up in disadvantage: A systematic review of qualitative evidence. Child Care Health Dev 2004; 30: 679-689.

64. Carroll C, Booth A, Lloyd Jones M. Should we exclude poorly reported qualitative studies from systematic reviews of qualitative data. Joint Cochrane and Campbell Colloquium 2010; Keystone, Colorado, USA.

65. Boaz A, Ashby D, Denyer D, Egan M, Harden A, Jones DR, Pawson R, Tranfield D. A multitude of syntheses: a comparison of five approaches from diverse policy fields. Evidence \& Policy 2006; 2: 479-502.

66. Zimmer L. Qualitative meta-synthesis: a question of dialoguing with texts. $J$ Adv Nurs 2006; 53: 311-318.

67. Pound P, Britten N, Morgan M, Yardley L, Pope C, Daker-White G, Campbell R. Resisting medicines: A synthesis of qualitative studies in medicine taking. Soc Sci Med 2005; 61: 133-155.

68. Harden A, Rees R, Shepherd J, Brunton G, Oliver S, Oakley A. Young people and mental health: A systematic review of research on barriers and facilitators. London, EPPI-Centre, Social Science Research Unit, Institute of Education 2001.

69. Rees R, Kavanagh J, Harden A, Shepherd J, Brunton G, Oliver S, Oakley A. Young people and physical activity: a systematic review matching their views to effective interventions. Health Educ Res 2006; 21: 806-825.

70. Shepherd J, Harden A, Rees R, Brunton G, Garcia J, Oliver S, Oakley A. Young people and healthy eating: a systematic review of research on barriers and facilitators. Health Educ Res 2006; 21: 239-257.

71. Berg RC, Denison E, Lewin S, Fretheim A. Integrating quantitative and qualitative evidence in systematic reviews: a mixed-methods approach. Cochrane Colloquium 2009; Singapore, Singapore.

72. Berg RC, Denison E. A tradition in transition: Factors perpetuating and hindering the continuance of female genital mutilation/cutting (FGM/C) summarized in a systematic review. Health Care Women Int 2012, doi: $10.1080 / 07399332.2012 .721417$

73. Pawson R, Greenhalgh T, Harvey G, Walshe K. Realist review - a new method of systematic review designed for complex policy interventions. J Health Serv Res Policy 2005; 10 (Suppl 1): 21-34.

74. Pawson R, Greenhalgh T, Harvey G, Walshe K. Realist synthesis: an introduction. ESRC Research Methods Programme; 2004. www.ccsr.ac.uk/methods/publications/documents/RMPmethods2.pdf (22.06.2013). 
75. Pawson R. Evidence-based policy. A realist perspective. London: Sage Publications, 2006.

76. Berg RC, Denison E. Methodological strengths and limitations of the realist synthesis approach to systematic reviews - A promising methodology for the Cochrane Collaboration? Cochrane Colloquium 2012; Auckland, New Zealand.

77. Barnett-Paige E, Thomas J. Methods for the synthesis of qualitative research: a critical review. BMC Med Res Methodol 2009; 9: 59.

78. Lucas PJ, Baird J, Arai L, Law C, Roberts HM. Worked examples of alternative methods for the synthesis of qualitative and quantitative research in systematic reviews. BMC Med Res Methodol 2007; 7: 4.

79. Candy B, King M, Jones L, Oliver S. Using qualitative synthesis to explore heterogeneity of complex interventions. BMC Med Res Methodol 2011; 11: 124.

80. Roberts KA, Dixon-Woods M, Fitzpatrick R, Abrams KR, Jones DR. Factors affecting uptake of childhood immunisation: A Bayesian synthesis of qualitative and quantitative evidence. Lancet 2002; 360: 1596-1599.

81. Voils CI, Hasselblad V, Crandell JL, Chang Y, Lee E, Sandelowski M. A Bayesian method for the synthesis of evidence from qualitative and quantitative reports: the example of antiretroviral medication adherence. $J$ Health Serv Res Policy 2009; 14 : 226-233.

82. Harden A, Thomas J. Methodological issues in combining diverse study types in systematic reviews. Int $J$ Soc Res Methodol 2005; 8: 257-271.

83. Harden A, Oakley A, Brunton G, Fletcher A. Integrating 'qualitative' studies and trials in reviews: reflections from reviews about teenage pregnancy, parenthood and social exclusion. Cochrane Colloquium 2005; Melbourne, Australia.

84. Harden A, Garcia J, Oliver S, Rees R, Shepherd J, Brinton G, Oakley A. Applying systematic review methods to studies of people's views: an example from public health research. J Epidemiol Community Health 2009; 58: $794-800$.

85. Goldsmith MR, Bankhead CR, Austoker J. Synthesising quantitative and qualitative research in evidencebased patient information. J Epidemiol Community Health 2006; 61: 262-270.

86. Petticrew M, Roberts H. Systematic reviews in the social sciences: A practical guide. Oxford: Blackwell, 2006.

87. Pope C, Mays N, Popay J. Synthesising qualitative and quantitative health research: A guide to methods. Maidenhead: Open University Press 2007. 